Session No. 3460

\title{
Instrumentation for A New Strength of Materials Laboratory
}

\author{
Mysore Narayanan \\ Miami University
}

\begin{abstract}
In order to provide the students with practical knowledge and hands-on laboratory experience, and with a view to emphasize the importance of bending moments and shear force diagrams, it was decided to create a new strength of materials laboratory for the engineering technology program at Miami University Hamilton Campus. The main objective was to encourage students to accomplish a variety of tasks, particularly in the area of materials science and strength of materials. However, the principal focus was to conduct detailed mathematical analysis pertaining to the study flexure of beams, with particular emphasis on bending moment and shear force diagrams, stress, strain, deflection, catenary curves and other properties. The students will be able to generate appropriate and relevant engineering data that would be successfully utilized in a real-world situation, such as building a bridge to transport heavy equipment.
\end{abstract}

In this project, the author reports on the results, accomplishments and milestones achieved. Eventually, when student groups work on their experimental project, they would be able to understand and appreciate the needs and necessities of engineering design methodologies. They will also be able to effectively utilize and apply the knowledge gathered and gained during the study period of several semesters, in a variety of courses. Whenever appropriate, comparisons are made and analogies are provided, so that the students will be able to identify the similarities that exist between mechanical, electrical and thermal models. While conducting and completing this experiment, the students are strongly encouraged to apply their knowledge of physics, chemistry, mathematics, electric circuit analysis, materials science, statics, strength of materials, dynamics, fluid mechanics, thermodynamics and heat transfer. Further, it was also essential that the new lab satisfied several key elements pertaining to Miami University's Plan for Liberal Education.

"Proceedings of the 2003 American Society for Engineering Education Annual Conference \& Exposition (C) 2003, American Society for Engineering Education" 


\section{ABET Engineering Criteria}

Criterion 3 of the ABET Engineering Criteria 2000 addresses "Program outcomes and assessment." The criterion requires that "Engineering programs must demonstrate that their graduates possess the following capabilities.

(a) An ability to apply knowledge of mathematics, science, and engineering.

(b) An ability to design and conduct experiments, as well as to analyze and interpret scientific and engineering data.

(c) An ability to design a system, component, or process to meet desired needs.

(d) An ability to function on multi-disciplinary teams.

(e) An ability to identify, formulate and solve engineering problems.

(f) An understanding of professional and ethical responsibility.

(g) An ability to communicate effectively.

(h) The broad education necessary to understand the impact of engineering solutions in a global and societal context.

(i) Recognition of the need for, and an ability to engage in life-long learning.

(j) Knowledge of contemporary issues.

(k) An ability to use the techniques, skills, and modern engineering tools necessary for engineering practice.

Miami University offers, both engineering and engineering technology programs, all within the umbrella of School of Engineering and Applied Science. It is therefore necessary to understand the criteria dictated by the engineering technology division of the ABET organization, as well.

\section{ABET TC2K Criteria}

Criterion 1 of the ABET Engineering Technology Criteria 2000 addresses "Students and Graduates." This criterion requires that an Engineering Technology program must demonstrate that their graduates possess the following capabilities.

(a) An appropriate mastery of the knowledge, techniques, skills and modern tools of their disciplines.

(b) An ability to apply current knowledge and adapt to emerging applications of mathematics, science, engineering and technology.

(c) An ability to conduct, analyze and interpret experiments and apply experimental results to improve processes.

"Proceedings of the 2003 American Society for Engineering Education Annual Conference \& Exposition (C) 2003, American Society for Engineering Education" 
(d) An ability to apply creativity in the design of systems, components or processes appropriate to program objectives.

(e) An ability to function effectively on teams.

(f) An ability to identify, analyze and solve technical problems.

(g) An ability to communicate effectively.

(h) Recognition of the need for, and ability to engage in lifelong learning.

(i) An ability to understand professional, ethical and social responsibilities.

(j) A respect for diversity and knowledge of contemporary professional, societal and global issues.

(k) A commitment to quality, timeliness and continuous improvement.

\section{Introduction}

The newly proposed strength of materials laboratory mainly concentrates on providing the students with the necessary background pertaining to the flexure formula. Flexure formula is discussed in detail, during lecture meetings and problem solving tutorial sessions. However, at present, students get very little hands-on experience. Further, the students, who have acquired the knowledge of electric circuit design and associated instrumentation techniques are required to apply their knowledge to the discipline of mechanical engineering. A long established principle is to be utilized by the student groups to incorporate foil strain gages in a Wheatstone bridge configuration. When a beam is not subjected to load, the experimenter was required to obtain null deflection on a galvanometer. In addition, when the beam was subjected to a load perpendicular to long axis of the beam, the galvanometer produces a reading. This reading is a measure of the beam deflection or bending moment developed inside the beam. There are plans to utilize an L.V.D.T. (Linear Variable Differential Transducer), also to measure the beam deflection. A portable strain-meter if available can be utilized to verify experimental data with theoretical calculations.

\section{Mechanical Transducers}

It is highly likely that the most common type of industrial instrumentation would require the measurement of pressure. This is primarily because pressure measurement can cover extremely wide range of signals and values. The application of any force, or pressure, will always produce a deflection, a distortion, or change in volume or some other dimension, no matter how small or large the force may be.

"Proceedings of the 2003 American Society for Engineering Education Annual Conference \& Exposition (C) 2003, American Society for Engineering Education" 
It is therefore essential for the students to understand that certain types of flow, level, and temperature measurements are really, indeed a form of pressure measurement. Various other topics can be discussed at length, however, this project mainly focuses on pressure measurements.

\section{Other Pressure Transducers}

Gages using electrical elements can be classified in terms of the range of pressure measured. In addition by applying these criteria they can be further classified. First, gages which use the rate at which heat is conducted away from the heated components as a measure of pressure. Second, gages which use the amount of ionization of the gas as a measure of its pressure. Thirdly, gages, which depend primarily upon the distortion or deflection of an elastic member to move another elastic member or to change the capacitance, mutual inductance, or resistance of a circuit. Next, gages which employ a change in resistance of a conductor to indicate pressure or gages, which employ magnetic or piezoelectric effects. Finally, instruments, which do not utilize any of the aforementioned methods. The first two are low-pressure instruments, while the remaining tend to be more middle of the road to high-end readings. Although both types of gages are extremely accurate, the electrical gages can generally measure lower absolute pressures than the mechanical-type discussed earlier.

The basic principle for the magnetic-circuit transducer is the replacement of air by some of the iron family. It is iron's ability to carry magnetic flux that makes it beneficial to this substitution. It can be concluded that with the addition of magnetic material to a winding, more flux will link the winding for any current in the winding. Thus an increased voltage of self-induction will result and the current will eventually be reduced. The flux is related to the frequency at which the coil is oscillating. As the flux varies with higher frequency, the voltage of self-induction increases linearly with the frequency too. The difference between the applied voltage and the induced voltage becomes less because of this action.

"Proceedings of the 2003 American Society for Engineering Education Annual Conference \& Exposition (C) 2003, American Society for Engineering Education” 


\section{Laboratory Objectives}

The newly established division of strength of materials laboratory is expected to fulfill the following objectives :

1. A complete and clear understanding of the way the flexure formula is applied to calculate maximum bending stress.

2. An understanding of the design methodologies involved.

3. The limitations under which the flexure formula can be applied.

4. Given load conditions, how to design a beam with safety considerations.

5. Knowledge of the effect of moment of inertia on bending stress.

6. Derive all necessary mathematical equations pertaining to the discussion.

7. Define: flexural center, section modulus and neutral axis.

8. An understanding of design stress and stress concentration factors.

9. Recommend different structural shapes as appropriate.

10. Provide Bending Moment and Shear Force Diagrams.

\section{Resistance Bridges}

Special circuits that are often used for making measurements of resistance, capacitance, and inductance are known as bridges. One of the most popular and most widely used bridge is the Wheatstone bridge. This is the configuration that is most widely adapted when the determination of a particular resistance value is required. It is considered to be fairly accurate $(0.1 \%)$ for measuring resistance values above one ohm. The Kelvin Bridge is preferred for measuring resistances below one ohm. The bridge works on the principle that no current will flow through the very sensitive d'Arsonval galvanometer connecting couple of points. The Wheatstone bridge was actually developed by Samuel Hunter Christie and it is logical it should have been named The Christie Bridge! A detailed mathematical discussion can be found in any standard textbook and is therefore not covered here.

\section{Data and Analysis}

Due to various unforeseen problems and circumstances beyond his control, the author is unable to provide complete details regarding this experimental set up, data acquisition, analysis and conclusions. However, a prototype was successfully tested with borrowed equipment and instrumentation.

"Proceedings of the 2003 American Society for Engineering Education Annual Conference \& Exposition (C) 2003, American Society for Engineering Education" 
It is hoped that funds will be available in the near future to successfully establish the laboratory for the benefit of the student population-beginning fall 2004. The author apologizes for the inconvenience caused. Upon successful completion of the laboratory sessions the students are expected to produce several graphs and analyze several sets of data.

Using flexure formula the students can analyze and calculate the strain developed during the loading of a beam. The deflection can be measured using an LVDT (Linear Variable Differential Transducer). A strain meter can also be utilized to determine the strain. It will be an interesting exercise to compare the theoretical values with the experimental values.

A sample graph that was generated using borrowed equipment is shown below. 
Strain vs. Deflection

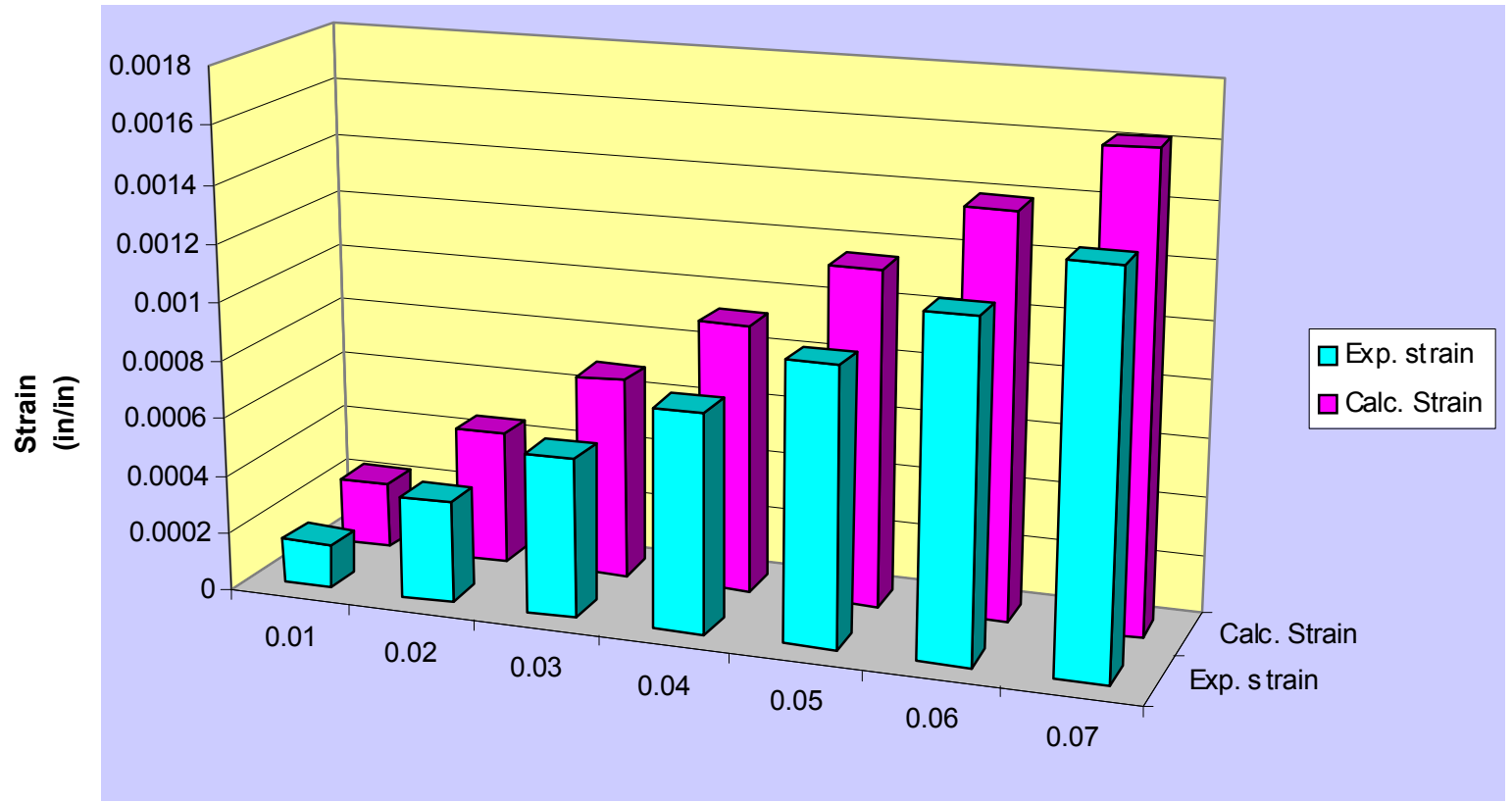

Deflection (in.)

"Proceedings of the 2003 American Society for Engineering Education Annual Conference \& Exposition (C) 2003, American Society for Engineering Education” 


\section{References :}

Montagu, Simon A.(2001) High-Technology Instruction: A Framework for Teaching Computer-Based Technologies. Journal on Excellence in College Teaching. Oxford, Ohio : Miami University. 12(1) 109-128.

Stefanou, Spiro E., Hood, Lamartine F. and Stefanou, Candica R. (2001) Feedback and Change: Assessment of Individual Contributions Within Collaborative Activities in the Higher Education Classroom. Journal on Excellence in College Teaching. Oxford, Ohio : Miami University. 12(2) 77-91.

Chapman, David W. Designing Problems for Motivation and Engagement in the PBL Classroom. Journal on Excellence in College Teaching. Oxford, Ohio : Miami University. 11(2) 73-82.

Ferrario, Larry S. Writing to Learn: Using Journals Across the Curriculum Journal on Excellence in College Teaching. Oxford, Ohio: Miami University. 10(3) 23-31.

Dorf, Richard C. and Svoboda, James A. (2000) Introduction to Electric Circuits ( $5^{\text {th }}$ Edition) New York: John Wiley \& Sons.

Dorf, Richard C. and Bishop, Robert H. (2002) Modern Control Systems (9th Edition) New Jersey: Prentice Hall Book Company.

Doebelin, Ernest O. (1990) Measurement Systems (4 ${ }^{\text {th }}$ Edition) : Applications and Design. New York : McGraw Hill Book Company.

Cerbin, W. (1992). How to improve teaching with learning-centered evaluation. The National Teaching and Learning Forum, 1(6), 8-9.

AAHE Assessment Forum. (1992). Principles for good practice for assessing students' learning. Washington, DC: American Association for Higher Education.

"Proceedings of the 2003 American Society for Engineering Education Annual Conference \& Exposition (C) 2003, American Society for Engineering Education”" 


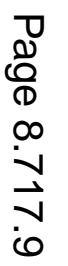

